\title{
Commentary \\ Impaired glucose and nutrient absorption in critical illness: is gastric emptying only a piece of the puzzle?
}

\author{
Alain Dive \\ Department of Intensive Care, Louvain School of Medicine, Mont-Godinne Hospital, 5530 Yvoir, Belgium
}

Corresponding author: A Dive, alain-michel.dive@uclouvain.be

Published: 1 October 2009

Critical Care 2009, 13:190 (doi:10.1186/cc8049)

This article is online at http://ccforum.com/content/13/5/190

(c) 2009 BioMed Central Ltd

See related research by Chapman et al., http://ccforum.com/content/13/4/R140

\begin{abstract}
This commentary highlights the contribution of the article by Chapman and colleagues assessing the relationships between glucose absorption, glycaemia and gastric emptying during critical illness. In addition to several more expected findings, their data suggest that factors other than slow gastric emptying may limit glucose absorption during critical illness. This hypothesis has received little attention so far, although numerous small intestinal abnormalities possibly interfering with absorption are known to occur in intensive care patients. Future work should focus on further validation of tools to assess nutrient absorption in the critically ill, before defining the precise causes and mechanisms that are involved.
\end{abstract}

In a recent issue of Critical Care, Chapman and colleagues [1] report a study aiming to quantify glucose absorption and the relationships between gastric emptying, glucose absorption and glycaemia in critically ill patients. This study follows many publications from the same Australian group that have contributed greatly to better our understanding of gastrointestinal failure during critical illness [2]. They analysed the kinetics of glucose absorption, glycaemia modifications, and gastric emptying after a test meal in 19 critically ill patients, with comparison to healthy volunteers. The test meal was administered by nasogastric bolus, however, a modality of administration somewhat different from the classic continuous intragastric infusion. Some of their findings were expected from previous work, while others clearly challenge our present beliefs.

In agreement with many previous studies [2,3], the rate of gastric emptying was reduced in critically ill patients and, consequently, the rate of glucose absorption was found to be reduced. Glucose absorption in this study was measured using 3-O methylglucose (3-O MG). Like glucose, 3-O MG is actively absorbed by enterocytes (through sodium glucose co-transporter-1), but it is not metabolized; therefore, kinetic parameters obtained from sequential plasma concentrations as well as urinary excretion following digestive administration have been used as markers of glucose absorption [4,5]. Since absorption of this sugar occurs almost exclusively in the intestine, gastric emptying should logically influence the rate of 3-O MG absorption after intragastric administration, an observation that Chapman and colleagues confirmed.

The finding that 3-O MG absorption is still decreased in the subset of patients with normal gastric emptying is more surprising, however, and calls out for additional explanation. Besides gastric emptying, numerous factors may theoretically influence the kinetics of 3-O MG absorption, including mucosal integrity, the number of sodium glucose co-transporters, small intestine peristalsis, blood flow, the volume of distribution of the substance, and alterations in renal clearance $[4,6]$.

The hypothesis of impaired intestinal absorption of glucose in critically ill patients has received little attention so far; indeed, many ICU physicians still consider that nutrients are absorbed completely provided that they have passed beyond the pylorus. Increasing evidence may indicate, however, that this concept is obsolete, and energy loss through malabsorption may be an overlooked problem in ICU patients. Using bomb calorimetry, a method to quantify the energetic losses in faecal material, investigators demonstrated substantial loss of calories in the faeces of ICU patients, most of them fed postpylorically [7]; in 13 patients with a faeces collector because of loose stools, the caloric value of energy loss was a mean of $301 \mathrm{kcal} /$ day, and 3 patients had a loss of more than $500 \mathrm{kcal} /$ day in the stools [7]. 
Decreased intestinal absorption in ICU patients may conceivably be multifactorial; gut mucosal atrophy and decreased splanchnic perfusion have been described extensively during critical illness. Also, digestive secretory function (essential for degradation of more complex nutrients) may be qualitatively or quantitatively affected, as neurohumoral control is frequently impaired. Furthermore, intestinal motility is possibly inappropriate for optimal digestion and absorption of nutrients due to the persistence of migrating motor complexes during feeding $[2,8]$.

Conducting studies assessing intestinal absorption in ICU patients is a difficult task. In particular, caution should be taken when interpreting the kinetics of 3-O MG (to represent glucose) absorption in the ICU setting. ICU patients do indeed show pharmacokinetic differences compared with normal individuals, including increased volume of distribution and variable clearance of substances $[9,10]$. In septic patients, the volume of distribution of hydrophilic substances is often greater due to an increased capillary permeability resulting in fluid shifts from the intravascular compartment to the interstitial space. Distribution volume may also be increased in ICU patients by the presence of mechanical ventilation, hypoalbuminaemia (increased capillary leakage), extracorporeal circuits, postsurgical drains, or burn injury [10]. The resulting effect would be a decreased plasma concentration of the molecule with a risk of misinterpretation of some important kinetic parameters (area under concentrationtime curve, maximal concentration, time to peak concentration). This may be of particular relevance if the sampling period is relatively short. To circumvent this problem, quantification of urinary excretion of the test substance during prolonged urinary collection may be preferable. Alternatively, the so called 'dual probe' method has been proposed; in this method, simultaneous administration of probe substances that respond in a similar way to variables such as extracellular fluid volume or renal clearance enables calculation of urinary excretion ratios, thereby eliminating the effect of these factors [4].

Another observation from Chapman and colleagues' study is the finding that gastric emptying was inversely related to baseline blood glucose, such that elevated blood glucose levels were associated with slower gastric emptying. This confirms previous data from animal as well as human studies demonstrating a deleterious effect of hyperglycaemia on gastric emptying [11]. Also, previous studies have suggested that small intestinal [12] and gallbladder motility [13] may be inhibited by a hyperglycaemic state. Glucose control may thus be important for optimal tolerance and absorption of nutrients in ICU patients.

Future work should thus aim to confirm whether absorptive capacity of the gut is indeed impaired during critical illness and to determine the causes and mechanisms of this. With this aim in view, further development and validation of tools enabling reliable assessment of nutrient absorption in the ICU setting would be eminently desirable.

\section{Competing interests}

The author declares that he has no competing interests.

\section{References}

1. Chapman M, Fraser R, Matthews G, Russo A, Bellon M, Besanko LK, Jones K, Butler R, Chatterton B, Horowitz M: Glucose absorption and gastric emptying in critical illness. Crit Care 2009, 13:R140.

2. Chapman MJ, Nguyen NQ, Fraser RJ: Gastrointestinal motility and prokinetics in the critically ill. Curr Opin Crit Care 2007, 13:187-194.

3. Heyland DK, Tougas G, King D, Cook DJ: Impaired gastric emptying in mechanically ventilated, critically ill patients. Intensive Care Med 1996, 22:1339-1344.

4. Zuckerman MJ, Menzies IS, Ho H, Gregory GG, Casner NA, Crane RS, Hernandez JA: Assessment of intestinal permeability and absorption in cirrhotic patients with ascitis using combined sugar probes. Dig Dis Sci 2004, 49:621-626.

5. Sharpstone D, Neild P, Crane R, Taylor C, Hodgson C, Sherwood $\mathrm{R}$, Gazzard B, Bjarnason I: Small intestinal transit, absorption, and permeability in patients with AIDS with and without diarrhea. Gut 1999, 45:70-76.

6. Martin GR, Meddings JB, Sigalet DL: 3-O methylglucose absorption in vivo correlates with nutrient absorption and intestinal surface area in experimental short bowel syndrome. JPEN 2003, 27:65-70.

7. Strack van Schijndel RJM, Wierdsma NJ, Van Heijningen EMB, Weijs PJM, de Groot SDW, Girbes ARJ: Fecal energy losses in enterally fed intensive care patients: an explorative study using bomb calorimetry. Clin Nutr 2006, 25:758-764.

8. Dive A, Miesse C, Jamart J, Evrard P, Gonzalez M, Installe E: Duodenal motor response to continuous enteral feeding is impaired in mechanically ventilated patients. Clin Nutr 1994, 13:302-306.

9. Boucher B, Wood C, Swanson J: Pharmacokinetic changes in critical illness. Crit Care Clin 2006, 22:255-271.

10. Roberts J, Lipman J: Pharmacokinetic issues for antibiotics in the critically ill patient. Crit Care Med 2009, 7:840-851.

11. Schvarcz E, Palmer M, Aman J, Horowitz M, Stridsberg M, Berne C: Physiological hyperglycemia slows gastric emptying in normal subjects and patients with insulin-dependent diabetes mellitus. Gastroenterology 1997, 113:60-66.

12. Björnsson ES, Urbanavicius V, Eliasson B, Attvall $S$, Smith $U$, Abrahamsson $\mathrm{H}$ : Effects of hyperglycemia on interdigestive gastrointestinal motility in humans. Scand J Gastroenterol 1994, 29:1096-1104.

13. Gielkens HA, Van Oostayen JA, Frölich M, Biemond I, Lamers CB, Masclee AA: Dose-dependent inhibition of postprandial gallbladder motility and plasma hormone secretion during acute hyperglycemia. Scand J Gastroenterol 1998, 33:1074-1079. 